\title{
Multiphase, Multicomponent Simulation for Flow and Transport during Polymer Flood under Various Wettability Conditions
}

\author{
Ji Ho Lee and Kun Sang Lee \\ Department of Natural Resources and Environmental Engineering, Hanyang University, Seoul 133-791, Republic of Korea \\ Correspondence should be addressed to Kun Sang Lee; kunslee@hanyang.ac.kr
}

Received 10 June 2013; Accepted 21 October 2013

Academic Editor: Shuyu Sun

Copyright ( $\odot 2013$ J. H. Lee and K. S. Lee. This is an open access article distributed under the Creative Commons Attribution License, which permits unrestricted use, distribution, and reproduction in any medium, provided the original work is properly cited.

\begin{abstract}
Accurate assessment of polymer flood requires the understanding of flow and transport of fluids involved in the process under different wettability of reservoirs. Because variations in relative permeability and capillary pressure induced from different wettability control the distribution and flow of fluids in the reservoirs, the performance of polymer flood depends on reservoir wettability. A multiphase, multicomponent reservoir simulator, which covers three-dimensional fluid flow and mass transport, is used to investigate the effects of wettability on the flow process during polymer flood. Results of polymer flood are compared with those of waterflood to evaluate how much polymer flood improves the oil recovery and water-oil ratio. When polymer flood is applied to water-wet and oil-wet reservoirs, the appearance of influence is delayed for oil-wet reservoirs compared with water-wet reservoirs due to unfavorable mobility ratio. In spite of the delay, significant improvement in oil recovery is obtained for oil-wet reservoirs. With respect to water production, polymer flood leads to substantial reduction for oil-wet reservoirs compared with water-wet reservoirs. Moreover, application of polymer flood for oil-wet reservoirs extends productive period which is longer than water-wet reservoir case.
\end{abstract}

\section{Introduction}

After primary and secondary oil recovery, there remains lots of oil in place in the reservoirs. To gain unrecovered oil in the reservoirs, additional flood, called enhanced oil recovery (EOR) method, is needed to be applied. Polymer flood has been known as one of the most widely used chemical EOR method. Increased viscosity of displacing fluid by adding low concentrations of water soluble and high molecular weight polymer into water produces the lower mobility ratio. Favorable mobility ratio improves the sweep efficiency so that oil recovery is increased.

Craig defined wettability as the tendency of one fluid to spread on or adhere to a solid surface in the presence of other immiscible fluids [1]. The influences of reservoir wettability on multiphase flow on porous medium and hence on oil recovery have been well known. The wettability of a rock controls the location, flow, and distribution of fluids within reservoir rocks [2], which affects the relative permeability and capillary pressure $[3,4]$. Therefore, the recovery of polymer flood in oil-wet reservoirs is totally different from that in water-wet reservoirs. Also, considerable hydrocarbon reserves are remained in mixed-wet or oil-wet reservoirs. Consequently, there is a necessity to better understand the effects of wettability on the oil recovery during polymer flood. Most of polymer flood studies have been carried out without considering wettability effect or focused on water-wet reservoirs with respect to field scale [5-7]. The investigations on the role of wettability on the various aspects of oil recovery during polymer flooding have been mainly based on the experimental works [8-10]. Therefore, there is need to conduct comprehensive numerical study on the flow and transport of aqueous and oleic phases during polymer flood under various wetting conditions on field scale.

\section{Mathematical Formulation}

Simulations of polymer flood were conducted with UTCHEM, which is a 3D, multicomponent, multiphase, 
compositional model of chemical flooding processes considering complex phase behavior, chemical and physical transformation, and heterogeneous porous media properties [11].

The basic mass conservation equation for components can be written as follows:

$$
\frac{\partial}{\partial t}\left(\phi \widetilde{C}_{\kappa} \rho_{\kappa}\right)+\nabla \cdot\left[\sum_{l=1}^{n_{p}} \rho_{\kappa}\left(C_{\kappa j} \mathbf{u}_{j}-\mathbf{D}_{\kappa j}\right)\right]=R_{\kappa},
$$

where $\kappa$ is the component index, $j$ is the phase index including aqueous $(w)$ and oleic $(o)$ phases, $\phi$ is the porosity, $\widetilde{C}_{\kappa}$ is the overall concentration of component $\kappa$ (volume fraction), $\rho_{\kappa}$ is the density of component $\kappa\left[\mathrm{ML}^{-3}\right], n_{p}$ is the number of phases, $C_{\kappa j}$ is the concentration of component $\kappa$ in phase $j$ (volume fraction), $\mathbf{u}_{j}$ is Darcy velocity of phase $j\left[\mathrm{LT}^{-1}\right], R_{\kappa}$ is the total source/sink term for component $\kappa$ (volume of component $\kappa$ per unit volume of porous media per unit time), $\mathbf{D}_{\kappa j}$ is the dispersion tensor.

The phase flux from Darcy's law is

$$
\mathbf{u}_{j}=-\frac{\mathbf{k} k_{r j}}{\mu_{j}} \nabla\left(p_{j}-\gamma_{j} h\right),
$$

where $\mathbf{k}$ is the intrinsic permeability tensor, $h$ is the vertical depth, $k_{r j}$ is the relative permeability, $\mu_{j}$ is the viscosity, and $\gamma_{j}$ is the specific weight of phase $j$.

To predict the reservoir behavior under multiphase condition, it is important to understand relative permeability of a reservoir rock to each of the fluids flowing through it. Relative permeability is assumed to be solely determined by own saturation and residual saturations and investigated by experimental and analytical methods [12]. Extensive studies have been conducted resulting in representative correlations between relative permeability, saturation, and other factors [12]. In this study, multiphase relative permeabilities are modeled with Corey-type functions [11]. Corey-type relative permeability is expressed with relative permeability on residual saturation, exponent defining the curvature of relative permeability, and residual saturation determining normalized saturation. Corey-type relative permeability equation is given as follows:

$$
k_{r j}=k_{r j}^{o} S_{n j}^{n_{j}} \quad \text { for } j=w, o,
$$

where $k_{r j}^{o}$ is the end point of relative permeability meaning relative permeability at residual saturation, $n_{j}$ is the exponent of relative permeability of phase $j$ determining the curvature of relative permeability, $S_{n j}$ represents the normalized saturation of phase $j$ calculated as follows:

$$
S_{n j}=\frac{S_{j}-S_{j r}}{1-\sum_{j=1}^{n_{p}} S_{j r}}
$$

where $S_{j}$ is the saturation of phase $j$ and $S_{j r}$ is the residual saturation of phase $j$.

Whether oil displaces water or water displaces oil through flow channels in reservoirs, flow phenomenon for immiscible fluid phases, oil and water, is involved with the pressure difference between these phases. Brooks and Corey observed a large number of data on consolidated rock cores and analyzed them by plotting the logarithm of effective saturation versus the logarithm of capillary pressure [13]. Due to this study, linear relationship between logarithm of effective saturation and logarithm of capillary pressure has been revealed and is shown as follows:

$$
\ln S_{e}=-\lambda \ln p_{c}+\lambda \ln p_{b} \quad \text { for } p_{c} \geq p_{b},
$$

where $S_{e}$ is the effective saturation calculated with residual saturations, $\lambda$ and $p_{b}$ are constants realized from intercept and slope, $\lambda$ means pore size distribution, $p_{b}$ is interpreted as maximum capillary pressure, the $p_{c}$ is the capillary pressure which represents pressure difference between wetting phase pressure and nonwetting phase pressure.

Capillary pressure is strong function of saturation as presented by (5). Leverett derived capillary pressure scaled by soil permeability and porosity for homogeneous reservoirs $[11,14]$. Reflected on previous relations, Brooks and Corey capillary pressure-saturation is calculated as follows:

$$
\begin{gathered}
p_{c}=p_{b} \sqrt{\frac{\phi}{k}} \text { for } j=w, o, \\
p_{b}=C_{p c}\left(1-S_{n j}\right)^{E_{p c}},
\end{gathered}
$$

where $E_{p c}$ is equivalent to $-(1 / \lambda), C_{p c}$ is constant, and $k$ and $\phi$ are the permeability and the porosity of the reservoirs.

\section{Numerical Modeling}

This study analyzes the effect of wettability on flow and transport of fluids during polymer flood. Reservoir wettability is implemented in the numerical model by changing relative permeability and capillary pressure curves simultaneously. The reservoir depth is $2,000 \mathrm{ft}$ and initial reservoir pressure is maintained at 400 psi. Horizontal area is $360 \times 360 \mathrm{ft}^{2}$ and vertical thickness of reservoir is $25 \mathrm{ft}$. The simulation domain consists of 10 layers and each layer is discretized into $15 \times 15$ grid blocks in horizontal direction. As close to production and injection wells, grid block has smaller size comparing with blocks which are away from wells to assess pressures and saturations more accurately near wells. The model assumes that the reservoir is homogeneous so the porosity and permeability are constant everywhere as 0.2 and $300 \mathrm{md}$ for horizontal direction and $30 \mathrm{md}$ for vertical direction. The initial saturations of oil and water are assumed to be constant for 0.62 and 0.38 , respectively. Properties of water and oil in reservoir are listed in Table 1. Water for injection is assumed to be identical as water in reservoir. Viscosity of polymeric solution including salinity and mechanical effects is considered as listed in Table 1.

The simulation was continued over 1,000 days. Injection designs for water and polymeric solution with conditions of constant rate are assumed to be identical for both waterwet and oil-wet reservoirs cases to access the performance of polymer flood quantitatively. To prevent high injection 


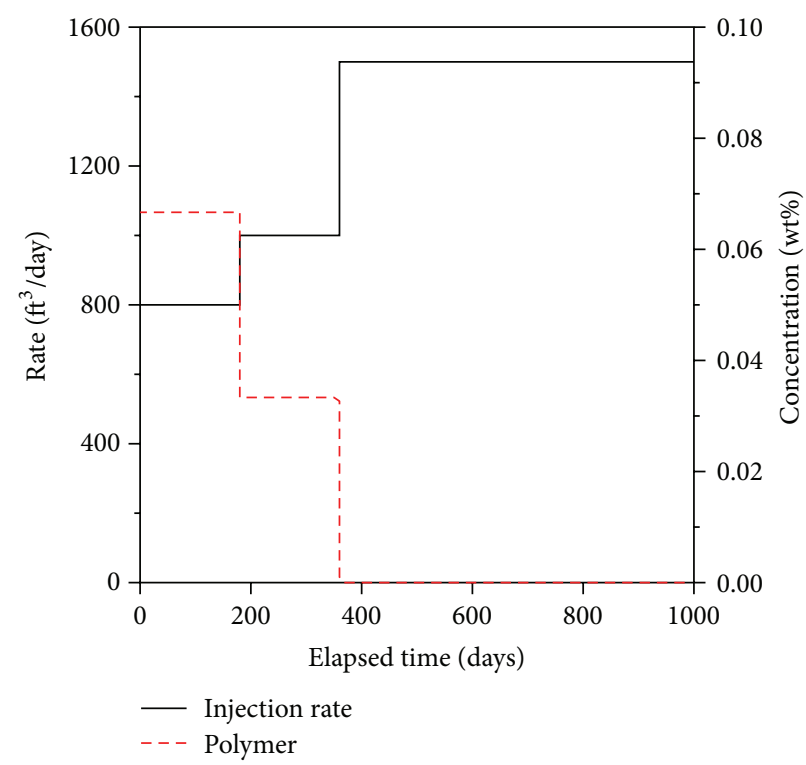

FIGURE 1: History of injection rate and polymer concentration.

TABLE 1: Properties of water and oil and viscosity of polymeric solution.

\begin{tabular}{lcc}
\hline Fluid & Water & $0.73 \mathrm{cp}$ \\
Viscosity $(\mu)$ & Oil & $40 \mathrm{cp}$ \\
Density $(\rho)$ & Water & $0.43353 \mathrm{psi} / \mathrm{ft}$ \\
& Oil & $0.385839 \mathrm{psi} / \mathrm{ft}$ \\
Compressibility $\left(C_{f}\right)$ & Water & $0 \mathrm{psi}^{-1}$ \\
& Oil & $0 \mathrm{psi}^{-1}$ \\
\hline Polymer viscosity & & \\
Parameters for zero & $A_{p 1}$ & $38.47 \mathrm{wt}^{-1}$ \\
shear viscosity & $A_{p 2}$ & $1,600 \mathrm{wt} \%^{-2}$ \\
& $A_{p 3}$ & $0 \mathrm{wt} \%{ }^{-3}$ \\
Parameters for effective & $\beta_{p}$ for $C_{\mathrm{SEP}}$ & 20 \\
salinity & $C_{\mathrm{SEP}, \min }$ & $0.01 \mathrm{meq} / \mathrm{mL}$ \\
& $C_{\mathrm{SEP}}$ & -0.3 \\
& $\dot{\gamma}_{c}$ & $130 \mathrm{day}$ \\
Parameters for shear rate & $\dot{\gamma}_{1 / 2}$ & $(\text { darcy })^{0.5} / \mathrm{ft} \cdot \mathrm{s}$ \\
dependence & $P_{a}$ & 280 \\
& & 2.2 \\
\hline
\end{tabular}

pressure due to increased viscosity of polymeric solution, injection of water and polymeric solution was operated in three steps as given in Figure 1. The flow rate of solution was constant at each step. In the first step, with $0.1 \%$ of polymer, injection was operated at low rate as $800 \mathrm{ft}^{3} /$ day to prevent fractures on the injection well until 180 days. In the next step, the concentration of polymer was reduced to $0.05 \%$, whereas the flow rate of injection was increased to $1,000 \mathrm{ft}^{3} /$ day by 360 days. In the last step, from 360 to 1,000 days, only water was injected through well by the end of operation. The reservoir fluids were recovered from the production well constrained with at 200 psi.

In order to analyze the effect of wettability on the flow and transport of fluids during polymer flood, comparisons were made for results from simulations implementing different relative permeability curves and capillary pressure curves. Relative permeability and capillary pressure are the most important factors that show the different performances of polymer flood applied to water-wet and oil-wet reservoirs. To model wettability effect, data for different relative permeabilities and capillary pressure curves are attained from several studies. Anderson derived an equation of Corey-type functions by curve fitting the data measured by Morrow et al. [15-17]. Table 1 lists fitted relative permeability parameters and Figure 2(a) shows relative permeability curves generated with the parameters.

Calculation of capillary pressure is based on Brooks and Corey equation as previously explained. Capillary pressure end point, $C_{p c}$, and capillary pressure exponent, $E_{p c}$, for water-wet and oil-wet reservoirs are listed in Table 2 [17]. Capillary pressures are also calculated with the data as shown in Figure 2(b).

\section{Results and Discussion}

Based on the simulation results, comparisons were made between the performances of polymer flood and waterflood applied to water-wet and oil-wet reservoirs. The results were presented with cumulative oil recovery, water-oil ratio, and oil saturation distribution of the fifth (middle) layer. To decide whether application of polymer flood for oil-wet reservoirs is effective or not, water cut was also analyzed.

Figures 3(a) and 3(b) present the cumulative oil recovery and water-oil ratio which was obtained from the application of waterflood and polymer flood to water-wet reservoirs. As 


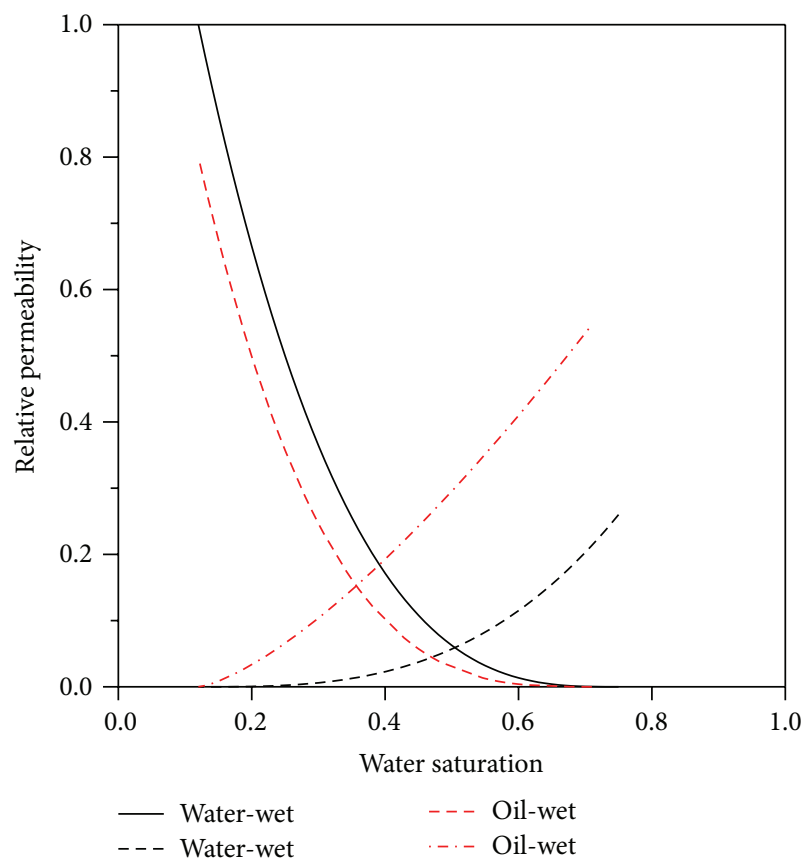

(a)

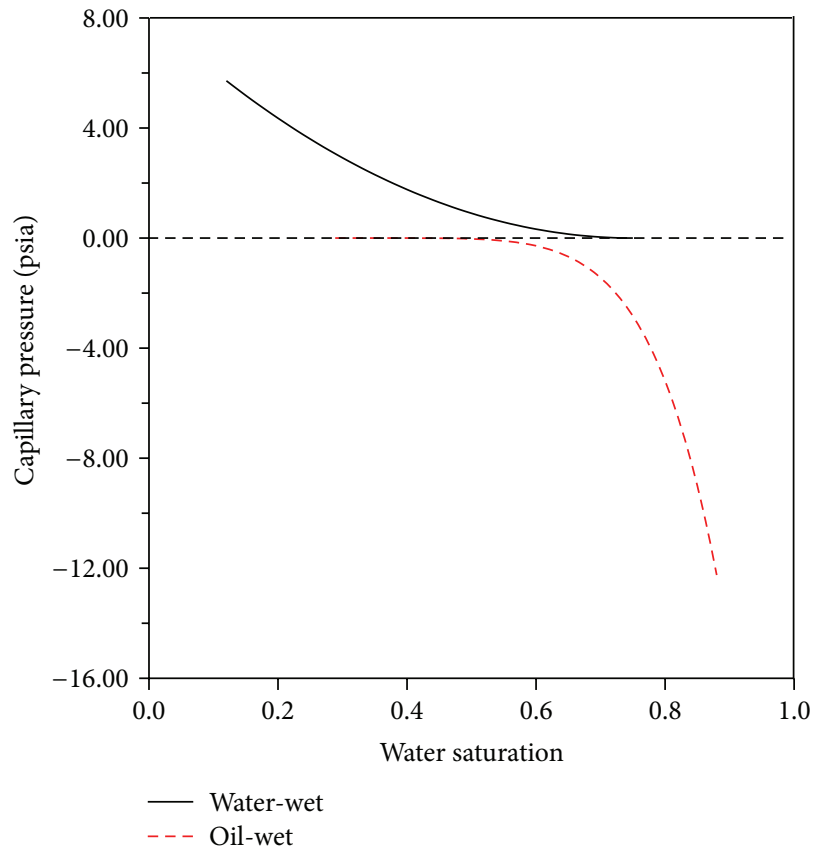

(b)

FIGURE 2: Properties of water-wet and oil-wet reservoirs: (a) relative permeability curves and (b) capillary pressure curves.

TABLE 2: Input parameters for capillary pressure and relative permeability depending on wettability.

\begin{tabular}{|c|c|c|c|c|c|c|}
\hline Parameters & $S_{w r}$ & $S_{o r}$ & $k_{r w}^{o}$ & $k_{r o}^{o}$ & $n_{w}$ & $n_{o}$ \\
\hline \multicolumn{7}{|c|}{ Relative permeability } \\
\hline Water-wet & 0.12 & 0.25 & 0.26 & 1 & 3 & 1.3 \\
\hline Oil-wet & 0.12 & 0.28 & 0.56 & 0.8 & 1.4 & 3.3 \\
\hline Parameters & & $C_{p c}$ & & & $E_{p c}$ & \\
\hline \multicolumn{7}{|c|}{ Capillary pressure } \\
\hline Water-wet & & 7 & & & 2 & \\
\hline Oil-wet & & -15 & & & 6 & \\
\hline
\end{tabular}

can be seen, the cumulative oil recovery by polymer flood is 0.58 , which is considerably higher than the oil recovery by waterflood, 0.40 , at the end of production. In terms of water-oil ratio, polymer flood results in lower water-oil ratio from 70 to 850 days, not from the initiation of injection. Even though polymeric solution is injected with a start of simulation, it takes time, 70 days in this model, to manifest the effect of polymer flood so that no improvement can be seen until 70 days. After 850 days, polymer flood already recovers almost movable oil in reservoirs, so that significant water production and lower increment of oil recovery are obtained. These improvements, higher oil recovery and lower wateroil ratio, during 70 days to 850 days result from increased viscosity of polymeric solution leading to lower or favorable mobility ratio. Furthermore, productive period is calculated to prove the influence of polymer flood applied to water-wet reservoir compared with waterflood case. The life span of production is determined with the assumption that producer is valid until it produces $90 \%$ of water cut. Considering results shown in Figure 5(a), polymer flood for water-wet reservoir sustains productive period of 160 days longer than that of waterflood case.

In attempts to study the effectiveness of polymer flood in oil-wet reservoirs, relative permeability and capillary pressure curves are set to be as Figures 2(a) and 2(b). Figures 4(a) and 4(b) compare the cumulative oil recovery and water-oil ratio between numerical simulations of polymer flood and waterflood for oil-wet reservoir. Application of polymer flood to oil-wet reservoir increases cumulative recovery as much as 0.36 which is higher than the result of waterflood case, 0.08 , and decreases water-oil ratio significantly. According to the calculation of productive period, while production by waterflood seems invalid for whole production period due to higher water cut as much as $90 \%$, polymer flood extends the life span of the well as much as 315 days as shown Figure 5(b). From the analysis of the average reservoir pressure in application of polymer flood shown in Figure 6, pressure profile for oil-wet reservoir has been maintained to be lower than water-wet reservoir. Due to the high viscosity of polymeric solution, pressure starts to be increased initially regardless of wettability. After post-flush as waterflood is applied, it is going to be decreased.

Despite of these effective performances of polymer flood for oil-wet reservoirs, utilization of polymer flood has not widely fulfilled. As shown in Figures 3 and 4, lower recovery and higher water-oil ratio are observed than those of waterwet reservoirs when both waterflood and polymer flood are applied to oil-wet reservoirs. In agreement with previous 


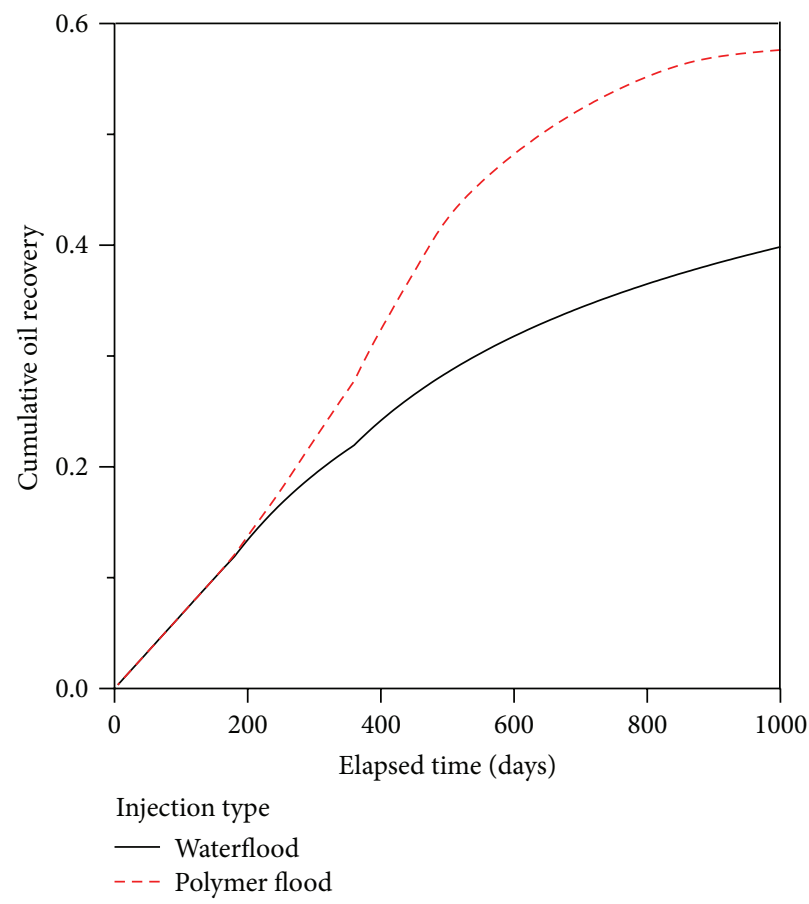

(a)

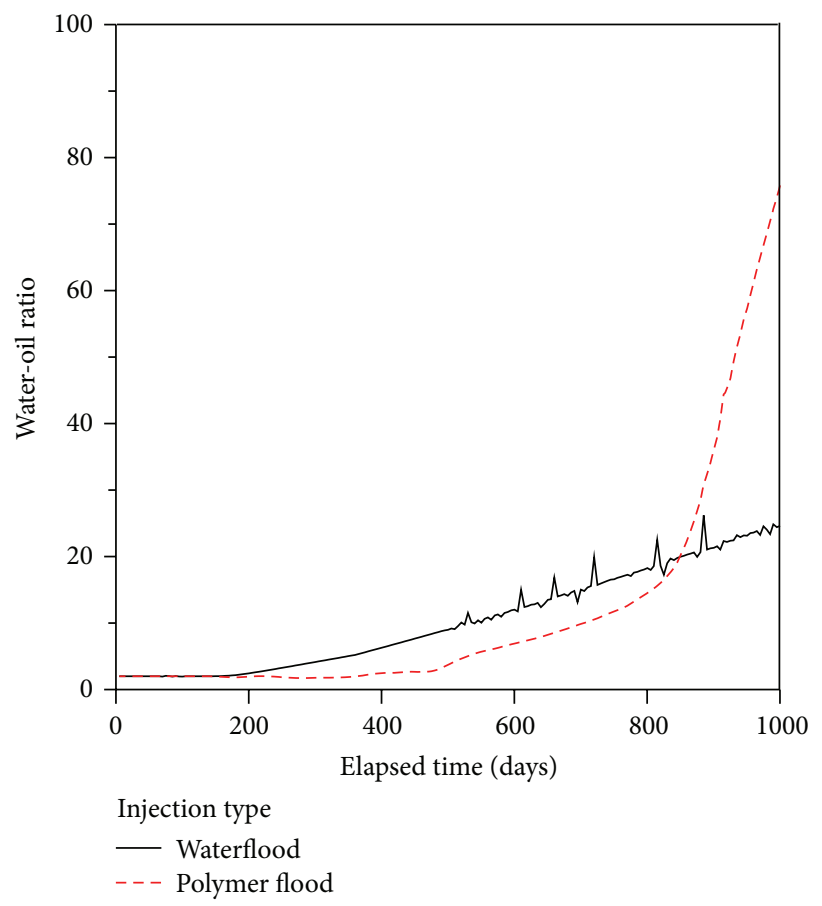

(b)

FIGURE 3: Comparison of waterflood and polymer flood for water-wet reservoir: (a) cumulative oil recovery and (b) water-oil ratio.

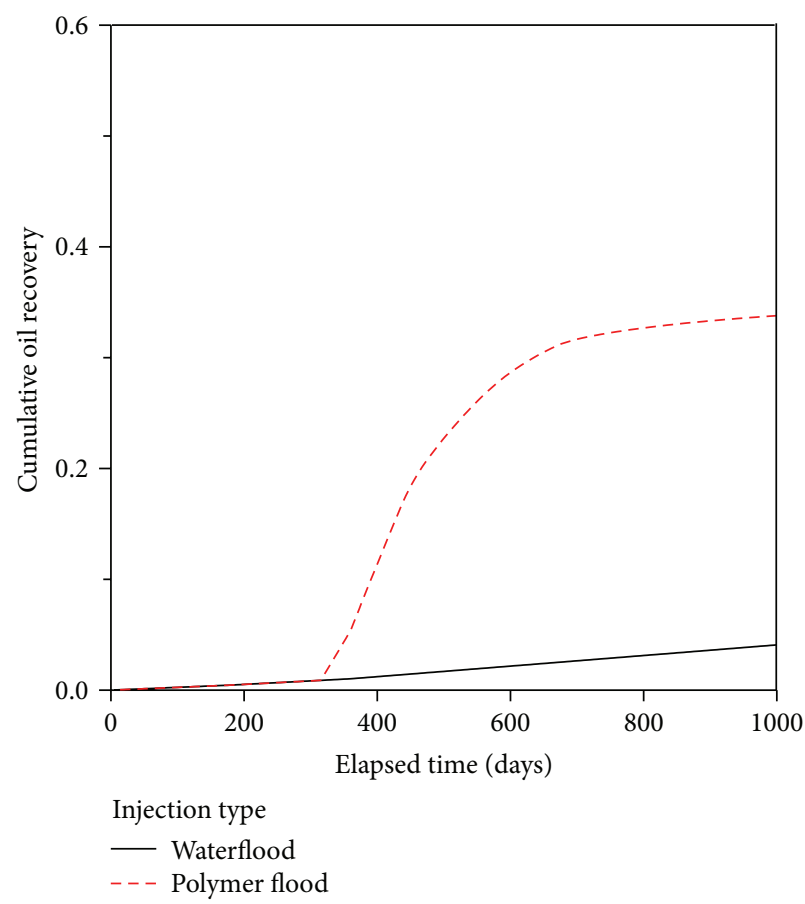

(a)

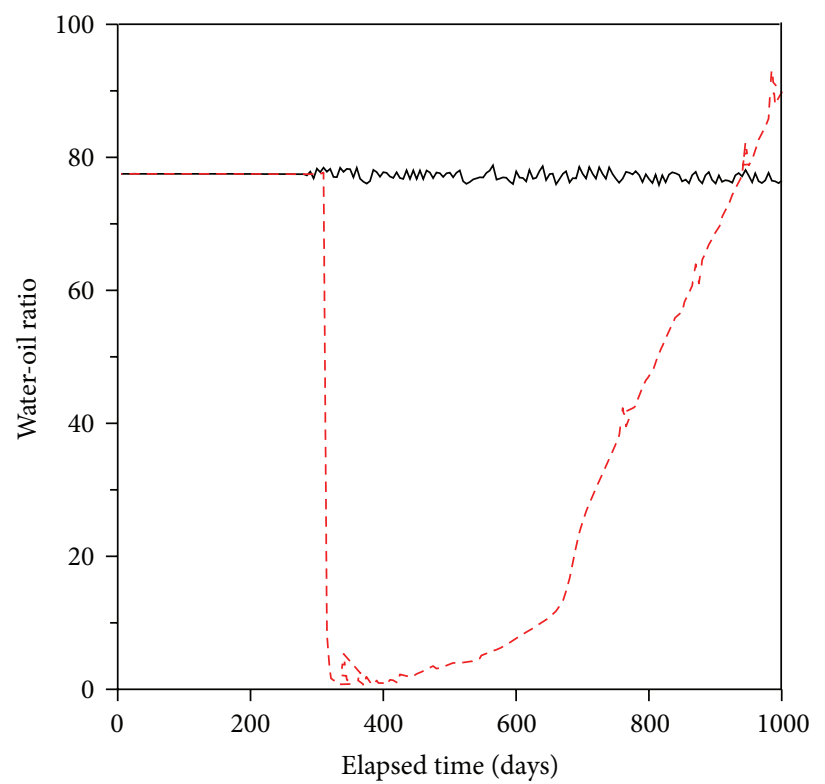

Injection type

— Waterflood

- - - Polymer flood

(b)

FIGURE 4: Comparison of waterflood and polymer flood for oil-wet reservoir: (a) cumulative oil recovery and (b) water-oil ratio. 


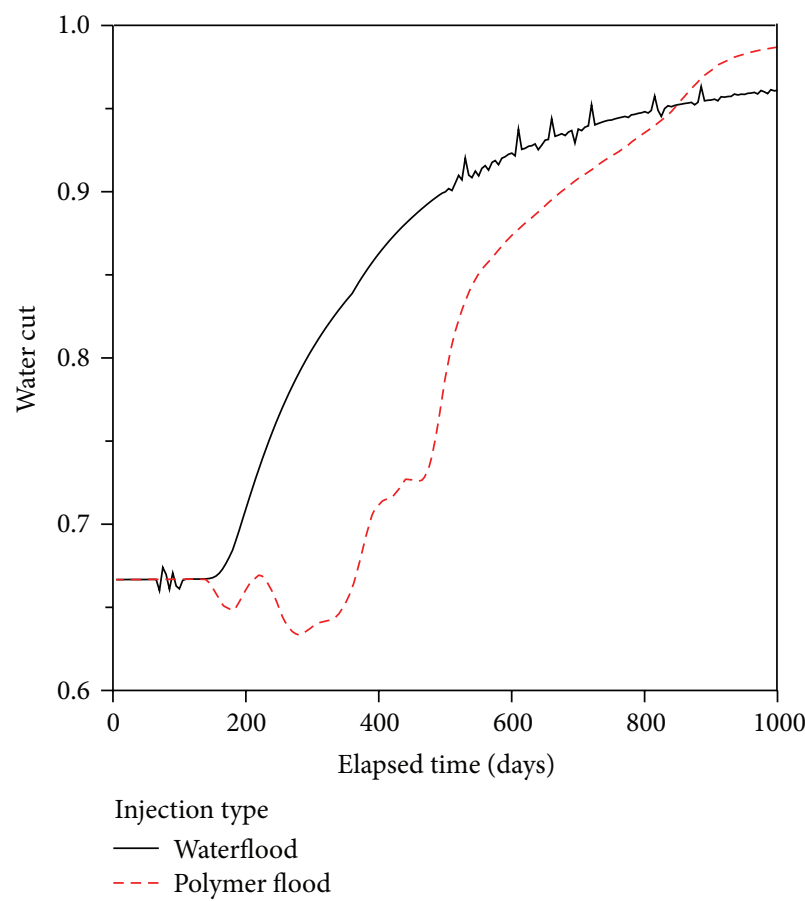

(a)

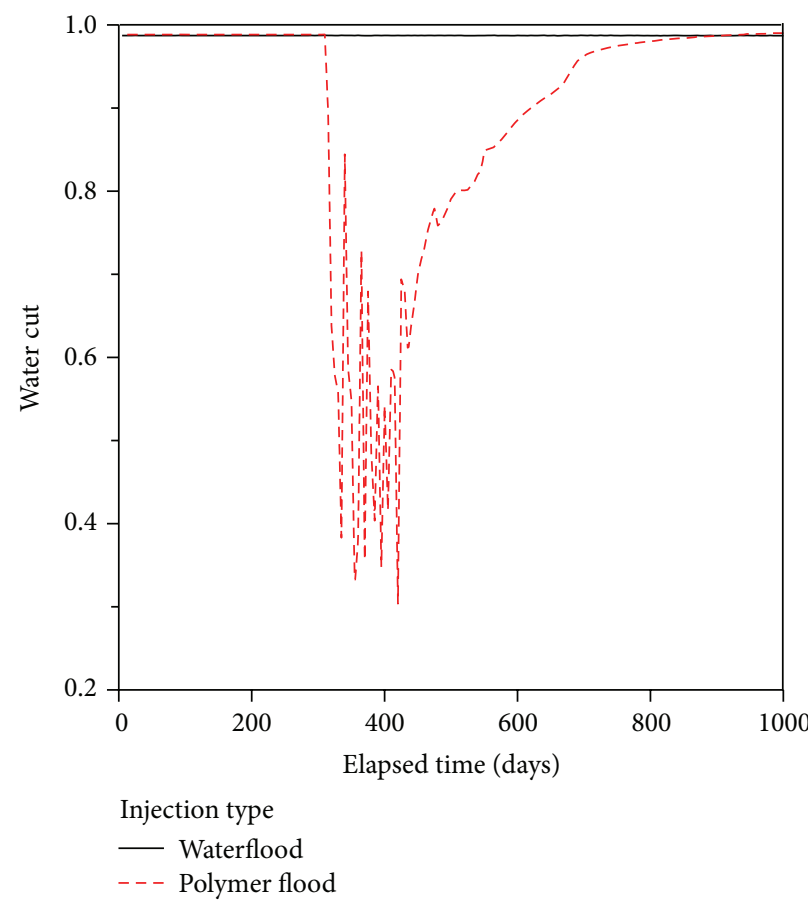

(b)

FIGURE 5: Water cut of waterflood and polymer flood depending on wettability: (a) water-wet and (b) oil-wet.

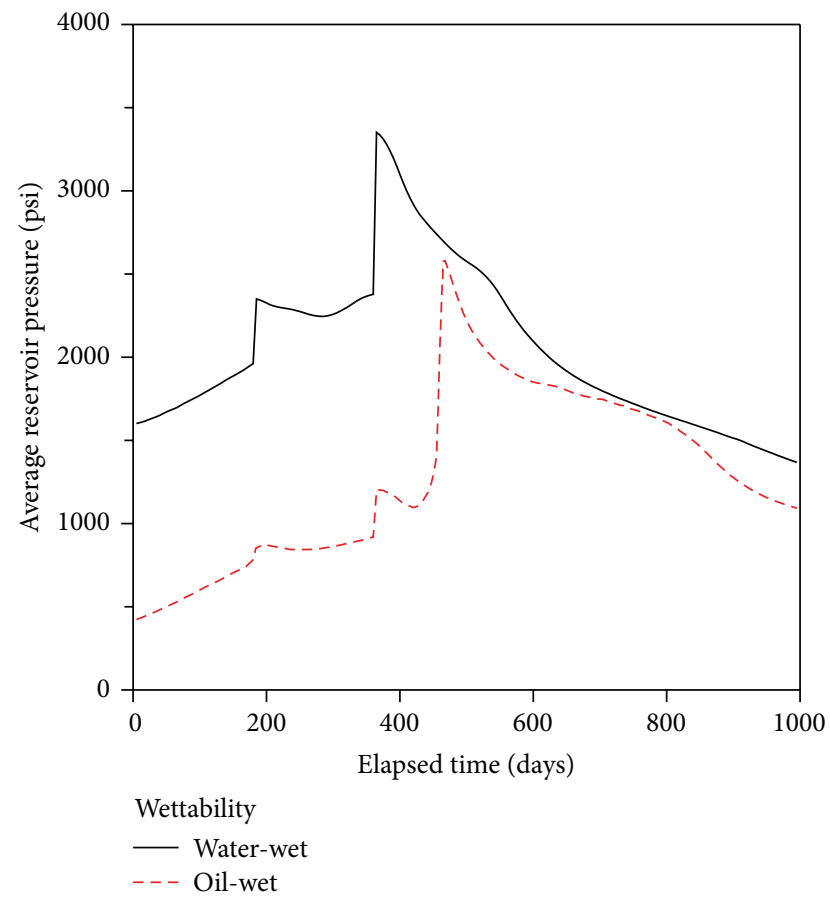

FIGURE 6: Average reservoir pressure profiles for polymer flood depending on wettability.

studies, the performance of polymer flood in oil-wet reservoir seems less effective than that in water-wet reservoir. These results could draw the conclusion that the application of

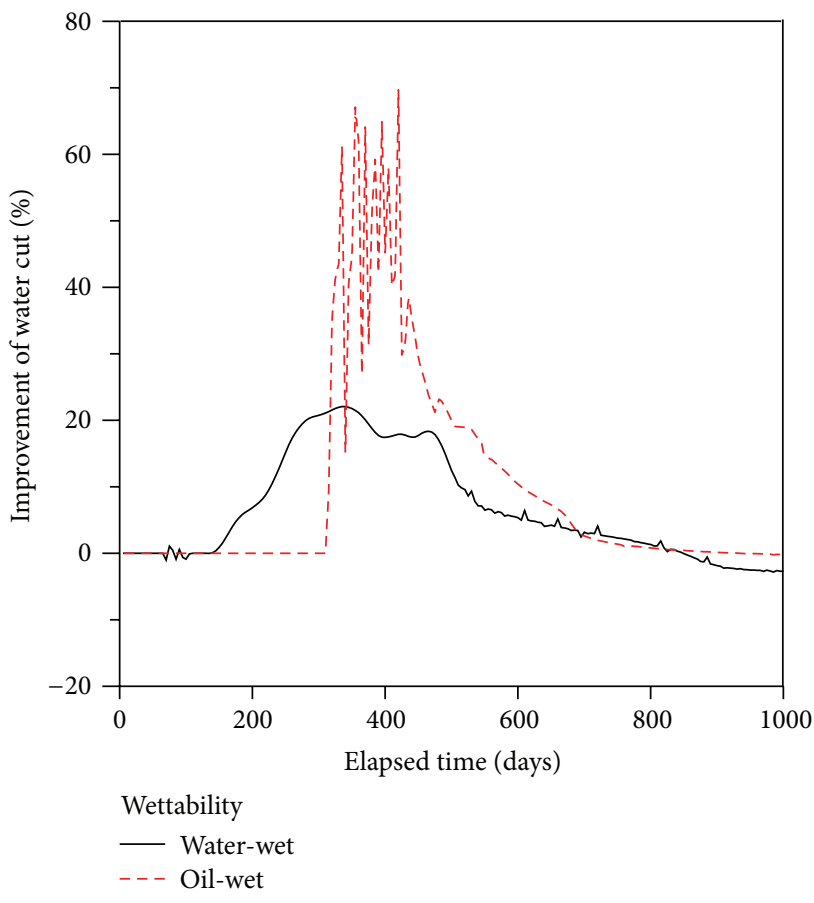

FIGURE 7: Improvement of water cut depending on wettability.

polymer flood to oil-wet seems not very effective and may not be recommended because it still shows low performance. However, not only the absolute value of oil recovery and water-oil ratio but also the improvement should be analyzed 


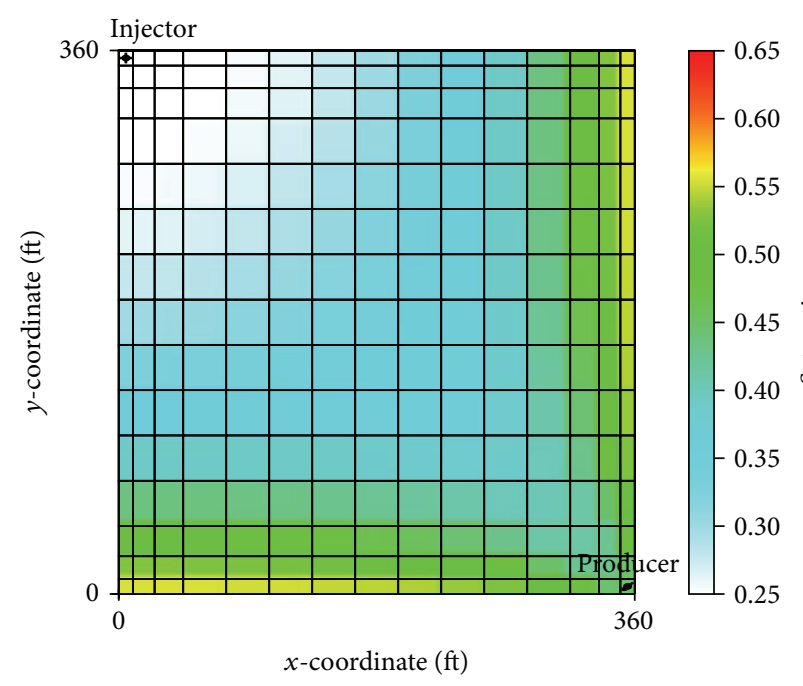

(a)

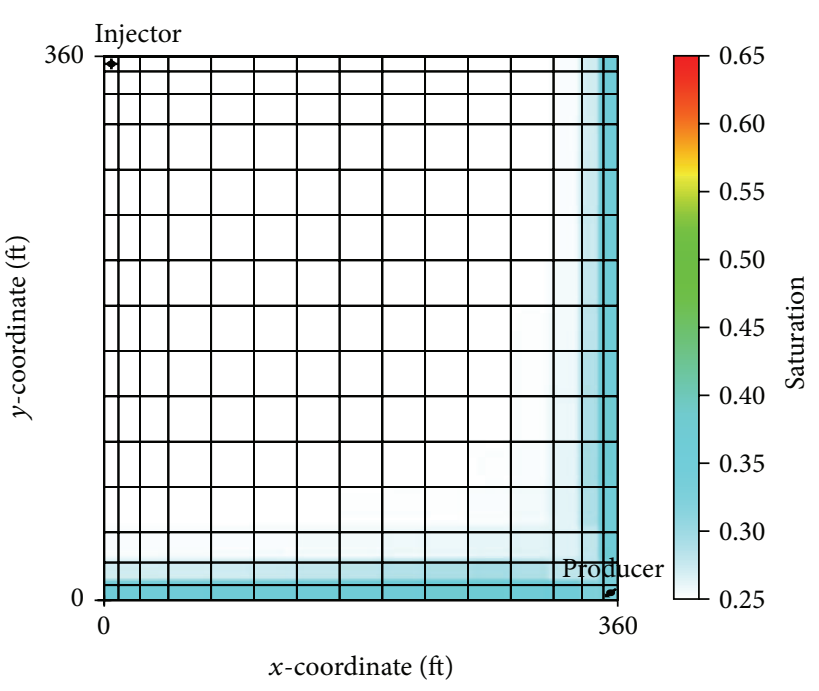

(b)

FIGURE 8: Comparison of oil saturation distribution in the fifth layer at 1,000 days for water-wet reservoir: (a) waterflood and (b) polymer flood.

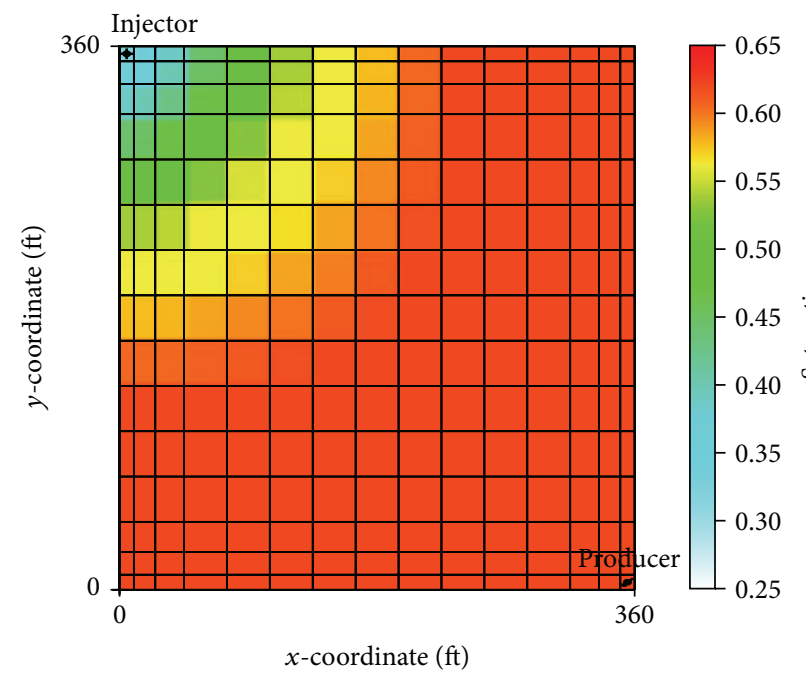

(a)

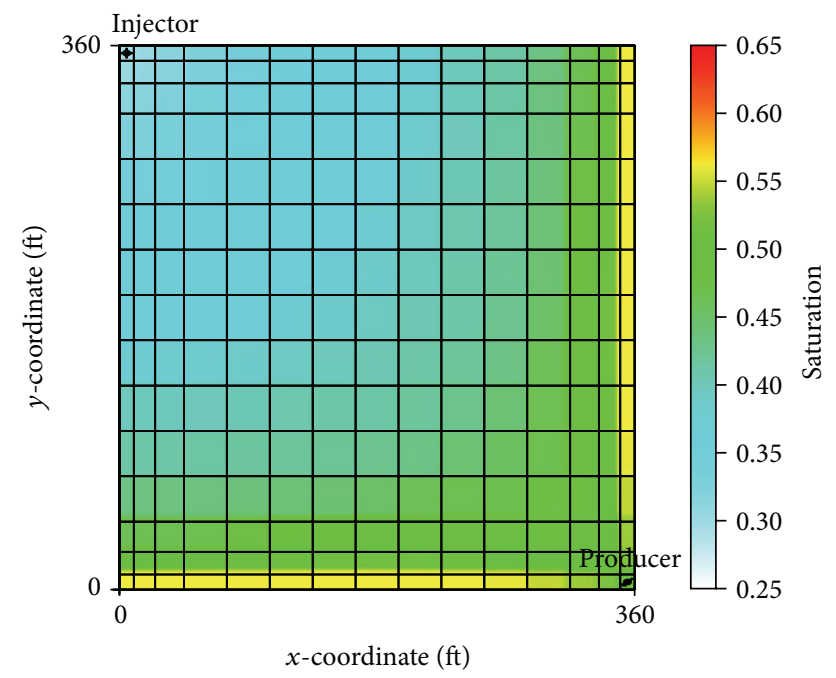

(b)

FIGURE 9: Comparison of oil saturation distribution in the fifth layer at 1,000 days for oil-wet reservoir: (a) waterflood and (b) polymer flood.

to consider efficiency of polymer flood. Therefore, additional analysis was repeated with respect to improvement by polymer flood. For water-wet reservoirs, polymer flood increases cumulative oil recovery up to $45 \%$ than that of waterflood from 0.40 to 0.58 . Polymer flood also reduces water-oil ratio at least $50 \%$ less than the waterflood case. If there is enough capability for waterflood to produce high performance, these improvements attained by polymer flood may not be so significant. Whereas, for the oil-wet reservoirs, the application of polymer flood leads to substantial improvement of oil recovery and extensive reduction of water-oil ratio compared with waterflood case due to low performance of waterflood. As shown in Figure 5(b), when waterflood is applied to oil-wet reservoirs, it already exceeds $90 \%$ water cut at the early stage and it increases up to $99 \%$. Because of high water production, waterflood should be suspended for oilwet reservoir. However, polymer flood reduces water-oil ratio as much as maximum $90 \%$ compared with waterflood case, so that it makes oil-wet reservoirs as fruitful. Moreover, polymer flood leads to increment of oil recovery as much as $351 \%$ at the end of production as shown in Figure 4. Additionally, analysis on improvements of water cut by polymer flood for different wettability is calculated and shown in Figure 7. Even though polymer flood for water-wet reservoirs represents the maximum reduction of water cut as much as $22 \%$, it results in reduction of as much as $80 \%$ for oil-wet reservoirs. Also, it sustains longer productive period as much as 315 days compared with that of water-wet reservoirs, 160 days, 
as shown in Figures 5 and 7. Therefore, the application of polymer flood results in more significant improvement in the case of oil-wet reservoir than in the case of water-wet reservoir.

Figure 8 compares remained oil saturation in the fifth layer in application of waterflood and polymer flood to waterwet reservoirs at 1,000 days or 1.98 pore volumes injected. Due to the favorable mobility ratio by polymer flood, relatively higher contrast of oil saturation between swept and unswept regions exits in reservoir. On the other hand, Figure 9 shows simulated oil saturation in the same condition like Figure 8, except for wettability as oil-wet reservoir. The overall oil saturation of polymer-flooded water-wet reservoirs is lower than that of water-flooded scheme and is almost close to residual oil saturation. For oil-wet reservoirs, remained oil saturation is still higher than residual oil saturation after polymer flood is applied. Nevertheless, the contrast of oil saturation distribution between before and after polymer flood is applied is clearly seen in oil-wet reservoirs rather than water-wet reservoirs.

\section{Conclusions}

According to multiphase, multicomponent simulation, polymer flood allows the mobility ratio between aqueous and oleic fluids to be favorable, which increases oil recovery and decreases water-oil ratio in both water-wet and oilwet reservoir conditions. The efficiency of polymer flood is remarkably affected by reservoir wettability. Performance of polymer flood for water-wet condition seems better than that for oil-wet condition. Because polymer flood is kind of modified waterflood, polymeric solution can displace oil out of the pore easily in water-wet scheme so that it sweeps lots of mobile oil and leaves just a little oil including residual oil saturation. This mechanism results in higher recovery for water-wet reservoir than oil-wet one. It could mislead us that polymer flood for oil-wet reservoirs is not effective as much as that for water-wet reservoirs. If anything, application of polymer flood to oil-wet reservoirs clearly shows higher improvement of oil recovery, water-oil ratio, and productive period than that of water-wet reservoirs. These results demonstrate that oil-wet reservoirs seem good candidates for the application of polymer flood because the technique is very effective in terms of the improvement of performance. Therefore, reliable evaluation of polymer flood should take into account wettability of reservoirs.

\section{Acknowledgments}

This work was supported by the Energy Efficiency and Resources of the Korea Institute of Energy Technology Evaluation and Planning (KETEP) Grant funded by the Korean government, Ministry of Trade, Industry and Energy (20122010300020).

\section{References}

[1] F. F. Craig, The Reservoir Engineering Aspects of Waterflooding, vol. 3 of SPE Monograph Series, Society of Petroleum Engineers, 1971.
[2] W. G. Anderson, "Wettability literature survey-part 1: rock/oil/brine interactions and the effects of core handling on wettability," Journal of Petroleum Technology, vol. 38, no. 11, pp. 1125-1144, 1986.

[3] W. G. Anderson, "Wettability literature survey-part 5: the effects of wettability on relative permeability," Journal of Petroleum Technology, vol. 39, no. 11, pp. 1453-1468, 1987.

[4] W. G. Anderson, "Wettability literature survey-part 4: effects of wettability on capillary pressure," Journal of Petroleum Technology, vol. 39, no. 10, pp. 1283-1300, 1987.

[5] Y. Du and L. Guan, "Field-scale polymer flooding: lessons learnt and experiences gained during past 40 years," in Proceedings of the SPE International Petroleum Conference, pp. 383-388, Puebla, Mexico, November 2004, SPE 91787-MS.

[6] X. Zhang, W. Guan, and F. Pan, "Polymer flooding for middle and low permeability sandstone reservoirs," in Proceedings of the the 6th International Petroleum Technology Conference, Beijing, China, March 2013, SPE 16536-MS.

[7] Y. Wang, Y. Pang, Z. Shao et al., "The polymer flooding technique applied at high water cut stage in daqing oilfield," in Proceedings of the the North Africa Technical Conference \& Exhibition, Cairo, Egypt, April 2013, SPE 164595.

[8] H. Xia, D. Wang, J. Wu, and F. Kong, "Elasticity of HPAM solutions increases displacement efficiency under mixed wettability conditions," in Proceedings of the SPE Asia Pacific Oil and Gas Conference and Exhibition, pp. 103-110, Perth, Australia, October 2004, SPE 88456.

[9] H. Dong, Y. Hong, W. Rui, and D. Fan, "The effect of wettability on oil recovery of alkaline/surfactant/polymer flooding," in Proceedings of the SPE Annual Technical Conference and Exhibition, pp. 2396-2403, San Antonio, Tex, USA, September 2006, SPE 102564.

[10] Y. Zhu, Y. Zhang, Q. Hou, H. Yuan, and G. Jian, "Effect of main factors on oil recovery of surfactant-polymer flooding," in Proceedings of the 6th International Petroleum Technology Conference (IPTC '13), Beijing, China, March 2013, IPTC16433.

[11] Center for Petroleum and Geosystems Engineering, UTCHEM9.0, a Three-Dimensional Chemical Flood Simulator, University of Texas at Austin, Austin, Tex, USA, 2000.

[12] A. T. Corey, "The interrelation between gas and oil relative permeabilities," Production Monthly, vol. 19, no. 1, pp. 38-41, 1954.

[13] R. H. Brooks and A. T. Corey, "Properties of porous media affecting fluid flow," Journal of the Irrigation and Drainage Division, vol. 92, no. 2, pp. 61-90, 1966.

[14] M. C. Leverett, “Capillary behavior on porous solids," Transactions of the AIME, vol. 142, no. 1, pp. 152-169, 1941.

[15] G. A. Anderson, Simulation of chemical flood enhanced oil recovery processes including the effects of reservoir wettability [M.S. thesis], University of Texas at Austin, Austin, Tex, USA, 2006.

[16] N. R. Morrow, P. J. Cram, and F. G. McCaffery, "Displacement studies in dolomite with wettability control by octanoic acid," SPE Journal, vol. 13, no. 4, pp. 221-232, 1973.

[17] M. Delshad, N. F. Najafabadi, G. A. Anderson, G. A. Pope, and K. Sepehrnoori, "Modeling wettability alteration in naturally fractured reservoirs," in Proceedings of the 15th SPE-DOE Improved Oil Recovery Symposium, pp. 1132-1140, Tulsa, Okla, USA, April 2006, SPE 100081. 


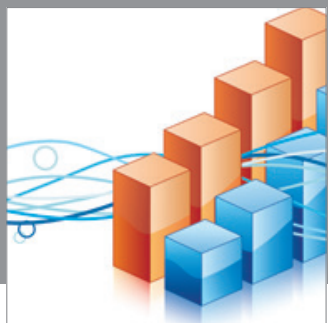

Advances in

Operations Research

mansans

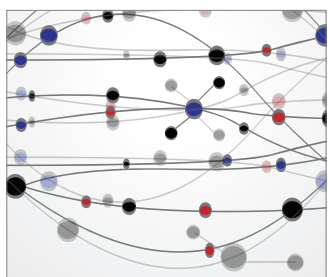

The Scientific World Journal
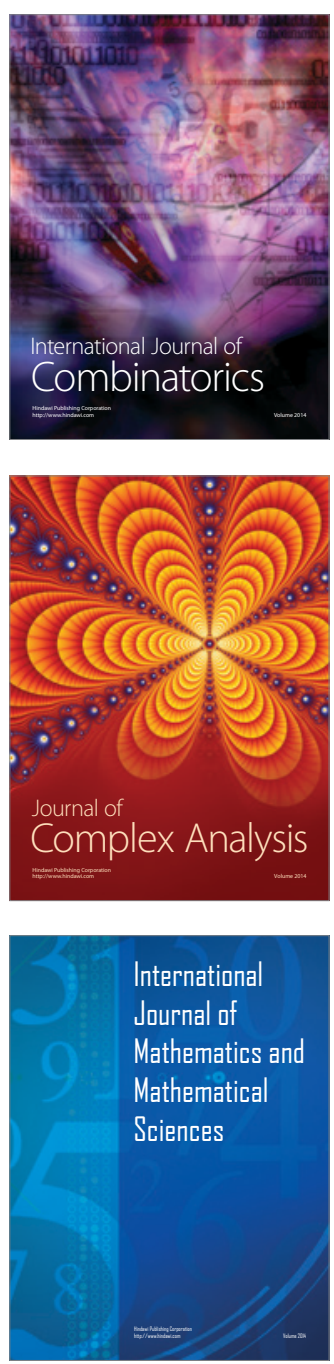
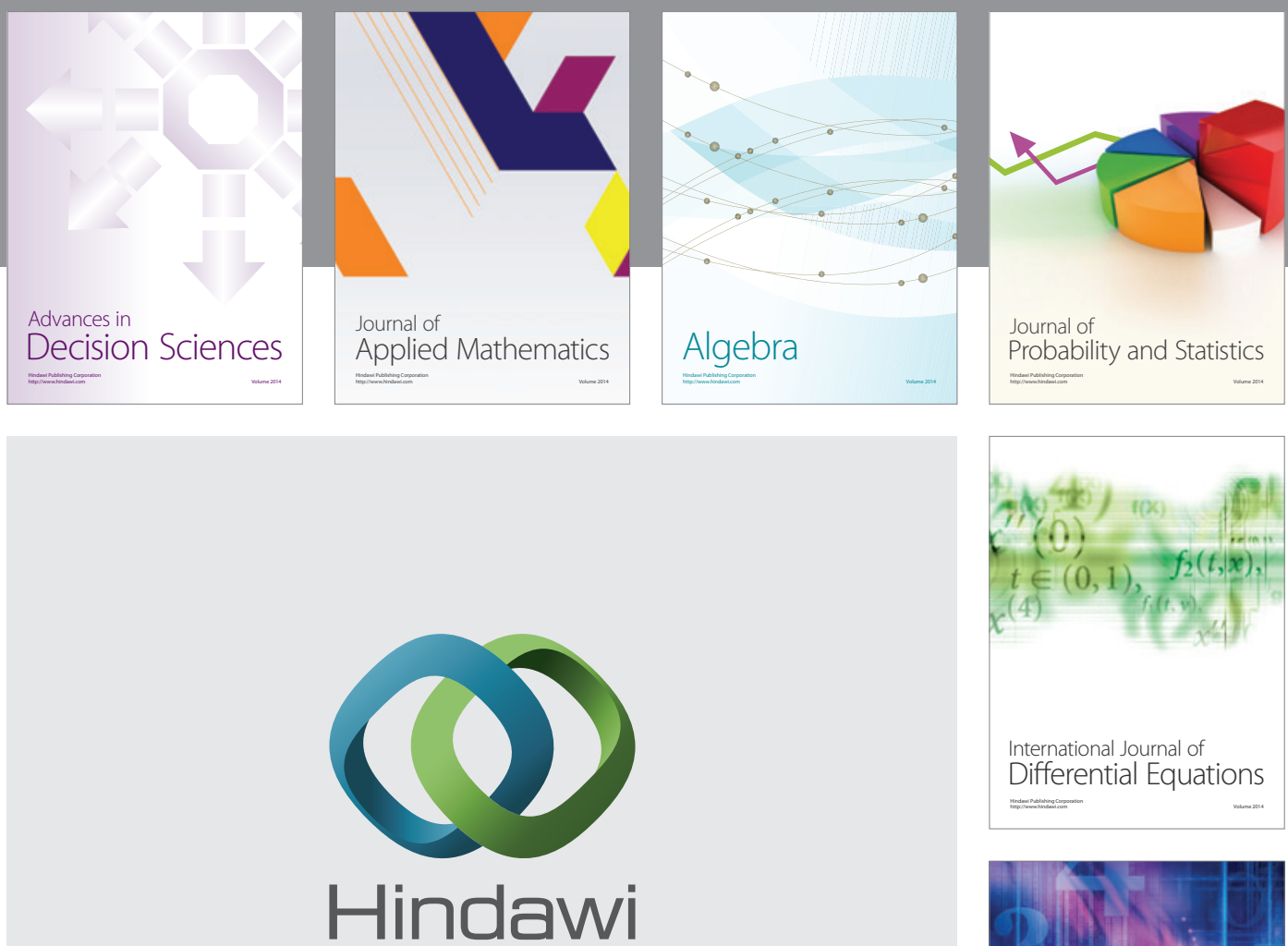

Submit your manuscripts at http://www.hindawi.com
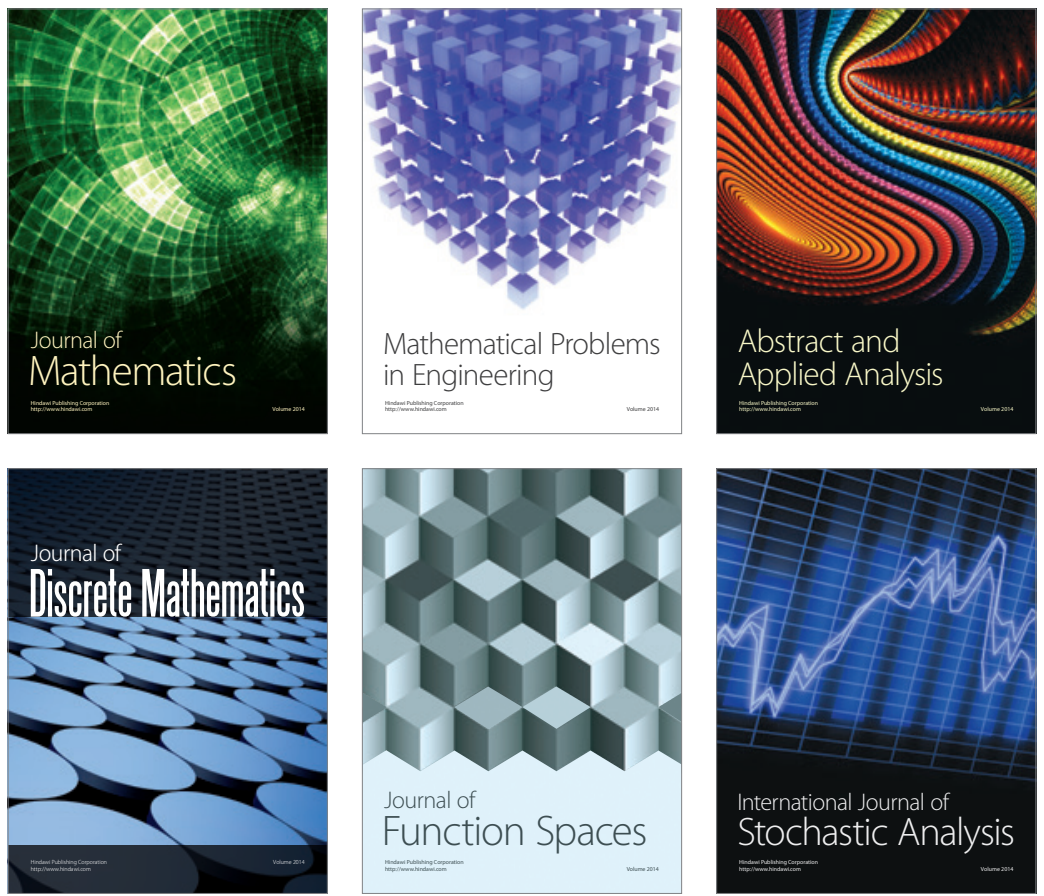

Journal of

Function Spaces

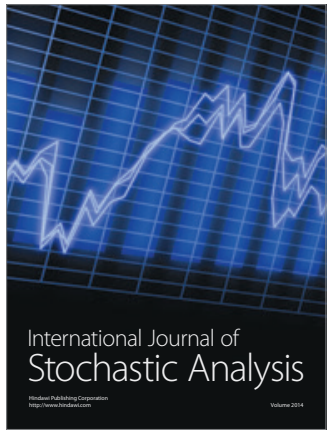

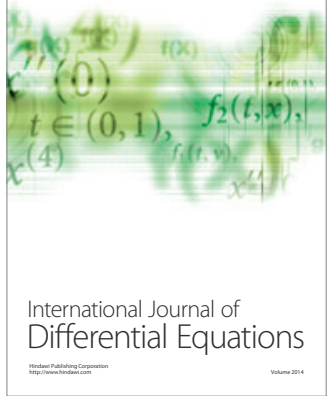
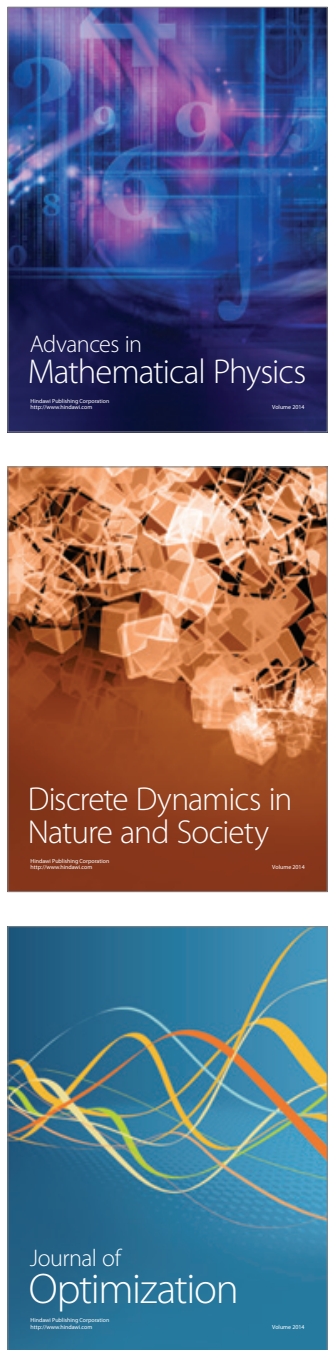